\section{Reducing Service Contract Costs and Do-It-Yourself EM Maintenance}

Owen P. Mills, Michigan Technological University

Service contract expenses constitute a large proportion of many EM laboratory budgets each year and managers, under constant pressure to reduce costs, no longer look at the expense as sacred. Increasingly, microscopists are faced with finding alternatives to the full service contracts they enjoyed so long. I facilitated a discussion group at the Microscopy \& Microanalysis ' 97 meeting held recently in Cleveland entitled "EM Maintenance: Can you do it yourself?" The audience of 50 represented microscopists from industry, academic and government facilities with a common interest - learning how to sensibly reduce service contract costs. In this article, I will offer my perspective on the subject and relate issues raised by the audience.

\section{Why even worry about reducing service contract costs?}

Simply put, more of us each year are finding out that we have no choice. Some, like myself, have had to deal with it earlier than others. The fact is, resources are drying up, and it is becoming clear that in order to pay for supplies next year, we may have to reduce service contract expenses. Some folks are confronting this for the first time, often unwillingly. One individual stated during the discussion: "I don't want to maintain or repair my microscope; that's not what I was trained to dol" Like it or not, taking on some responsibility for maintenance may mean the difference between keeping our jobs or not.

\section{Why are service contracts so costly?}

Although this was not a topic of discussion, it is appropriate to consider in this article. Think of microscope service as insurance and notice that as with any other form of insurance, the premium is related in some way to the claim rate. Reduce the claim rates - reduce the premiums. Realistically, we can expect the cost of service contracts to rise equal to or higher than inflation in spite of our hopes that technology would have lead us to "maintenance free" instruments. The problem is, we expect microscope manufacturers to work miracles! First we ask them to bring last year's breakthroughs to the market place this year, AND we expect them to produce and sell enough units to create a electron microscope version of the $V W$ bug. It is costly to maintain an international service organization. Some believe that service departments should not be profit-making. This is not realistic given the fact that as investors we expect a good rate of return from any other business! The answer is to reduce the claims. In our field that means reducing the number of calls for unnecessary service.

\section{What service options are available?}

This was another major topic discussed by the group. Vendors of service include the microscope manufacturer and third-party companies often operated and staffed by ex-manufacturer field service engineers. Both providers offer full service contracts under which non-consumable parts and on-site visits for emergency service and routine maintenance are covered.

Few in the audience were aware that most, if not all, manufacturer service organizations offer reduced or discounted service contracts. Many will tailor the contract to your needs. The fact is, the manufacturer wants to keep your business and is looking for economically viable ways to accomplish that. These contracts limit both the on-site service time and parts, so they are not for everyone. You should expect to take on some of the responsibility for routine maintenance and repairs yourself, with the company's help via telephone. Please note that contracts that depend in some way on your skills represent an unknown to the service provider. If things do not go well, i.e., your scope is down most of the time or you run out of on-site hours early in the period, the contract may not be renewed next time. More on doing it yourself later in the article.

In some cases there may be cost savings associated with third-party service vendors, although some in the audience related stories and fears of third-party vendors not being able to acquire unique or hard to find parts. For the record, the manufacturer cannot refuse to provide you or your third-party service provider with a part. They can, however, take their time getting it to your service provider. Contact your salesman in this situation. At some point in the manufacturer's organization, service and sales problems end up on one person's desk! Actually, third-party service may be the only option in cases where the manufacturer is unable (as in out-of-business) or unwilling to provide an experienced engineer for an older instrument. It is rare, however, to find a third-party service company that offers full service on late model instruments; they usually do not have staff with the expertise to do it right.

Do not forget that all service providers offer demand service; that is, they charge by the visit. The meter starts running when the engineer gets in the car to make his/her way to your site and parts are charged at list price. Even if you work in a city or area where the service office is located, expect to pay $\$ 1,000$ per day or more plus travel and parts for demand service. Also understand that you are not a priority; contract customers are. You may have to wait a few days to get an engineer on-site.

How you pay for service is changing too. Often, in an effort to keep your business, manufacturer service organizations may occasionally (not regularly) be willing to break your annual contract up into two six-month contracts. This helps when you have cash flow problems. Do not expect this nicety to be free: there is an up-charge for the service. A new option recently made available is an insurance policy on your scope provided by a risk management company. Cost savings are advertised as a benefit. You choose the service vendor and have them make the repair and then send the bill to the "insurance company".

"We don't have the funds to pay for the full service contract next year", says your boss. What do you do? First, you are not alone; there were several people in the audience in this situation and the group discussed ways to deal with it.

Make the case to management in a report stressing that prudence dictates planning ahead. First, you have to consider what level of reduced service you could accept with even under ideal circumstances. Assess your skills in this regard - can you handle even some of the responsibility for carrying out small repairs and maintenance? Be honest with yourself. Do not get in over your head. Look at the service reports for the last several years and estimate what the demand service costs might have been for the problems you observed. Construct a report that outlines the costs and benefits associated with a change in service arrangements. Do not forget to include opportunity costs such as a big loss of your time to maintenance/repair and training (more later on this). Apprise your service provider of the situation and get their help.

What should you expect to accomplish with this report? You may convince the administration/management that the idea is too costly and they should look harder for funds. Minimally, you may justify the expense of a reduced contract, hopefully after another year of full service while you prepare.

\section{How do I prepare?}

Identify resources for information that may help when it is your responsibility to fully align the scope, clean the aperture or even change an 0 -ring. The most valuable resource you have is your operator's manual. In it are detailed instructions to carry out most basic repairs and maintenance. In fact, if more of us had used this information and followed through, it is possible that service contract costs might be lower today. We should all be able to replace filaments and even apertures, align the scope, check and maintain our chiller, etc.

Next, answer this question:

"When the service engineer is on-site I am: a) catching up on more important job activities; b) on vacation; c) beside him/her watching and learning about how my scope works and is maintained.

The correct answer is $\mathrm{C}$, of course, although suddenly perching on your service engineers shoulder may startle him/her, so take it easy at first. Give them room and time to work. Remember your engineer's boss wants hirn/her to get your scope working and then move on to the next site. Just watch and ask a few questions. 
Take notice that when the engineer is on site to repair a problem, he/she will always refer to notes and old service reports. The lesson is, keep those reports! They are like gold; I keep them in a binder in chronological order.

If you are serious about learning more about your microscope, why not learn more about electronics. Even the basics are invaluable. Your local vocational technical school will offer evening courses in this area. Your boss might even be willing to pay for the training. In case it has not occurred to you, electronics training coupled with your skills as a microscopist makes you even more valuable and less likely to be a victim of staff cuts!

\section{How can I minimize the need for repairs?}

This question will occur to you soon after you begin preparing for the transition. The thought stream may go like this: "I'm going to have to find lost apertures now!" or "I will be retrieving grids dropped into the specimen chamber." Regardless of what reduced service route you decide on, it will be more important than ever to minimize breakage. Often breakage is attributable to inexperienced and untrained users and is especially a problem in multi-user facilities. When it is you who are responsible for repairing the problems caused by untrained users, you will make sure the users are trained! (Even if it is you who needs the training.) Prepare an operator's handbook for users that provide "cookbook" style instructions for the basics such as start-up, routine operation and shutdown. Require a certification course before use. It will take time to get this off the ground but unending repairs will consume more time if you do not do it! Reduced service contracts will be unsuccessful in a multi-user facility if users are untrained!

Knowing your instrument will pay off now. This falls under the category "Monitoring Your Microscope". Again, your scope came with a specification sheet. Use it. Make and record measurements of beam and lens stability, magnification calibration of the viewing displays and photo system, and ultimate vacuum and pump-down time of the vacuum system. You have a real vacuum gauge, right?

\section{Showtime!}

The contract renewal anniversary date has passed, and you are on the new system. You are keeping an eye on users (you included) to minimize breakage and have a regular schedule to monitor microscope performance.

Then it happens - you find an entry in the logbook stating that the scope is not working properly. STOP. Before you call for phone assistance or a service call when you think you have a problem, remember many problems are actually what I call "cockpit errors"; that is, there is a control in a strange position preventing the scope from behaving as you expect. Double-check all the controls before concluding there is a malfunction. (This is an excellent reason to have a section in your newly-created operator's handbook dedicated to standard knob and switch positions.) TIP: If you have a reduced contract, remember that unused on-site hours may be used for routine maintenance at year's end.

When you do call, make notes and be prepared to answer questions about the symptoms you observe. Narrow down the problem's source to a sub-system if possible and remember that the sub-systems have been designed to work, in many cases, independently of each other. A film transport problem is not likely to be related to the lenses. Do not identify parts as "dodads" or "whatchacallits"; learn the correct name of the component so there is no misunderstanding.

\section{What resources are available?}

I cannot over-emphasize the importance of using the basic resources you already have: i.e., the instruction manual and other documents you received with the microscope. With it you can learn a tremendous amount about how the instrument is constructed, what it is designed to do, and how it does it. The maintenance topics covered in your manual may be within your capabilities. Watch your engineer perform the steps, make notes and proceed cautiously.

The only book I can recommend that directly addresses maintenance for the TEM is Chapman's Monitoring and Maintaining the Transmission Electron Microscope. Use one of several texts available to gain a better understanding of the theory behind SEM or TEM. I use Goldstein's Scanning Electron Microscopy and X-Ray Microanalysis, 2nd Ed. for SEM theory and practice, and for TEM I use Transmission Electron Microscopy by Williams and Carter. Wilbur Bigelow's book, Vacuum Methods in Electron Microscopy is an excellent resource for vacuum technology. I recommend Eugene Bertin's Principles and Practices of $X$-Ray Spectrometric Analysis for microprobe and other wavelength dispersive spectrometry technologies.

Another extremely valuable resource is the World Wide Web. Through the Web, you can quickly locate and communicate with other users of microscopes like yours who may (or may not) be more knowledgeable about maintenance repair issues. The Microscopy Society of America and the Microbeam Analysis Society both operate web sites and listservers. The Microscopy Listserver provides a forum for the discussion of topics of interest to all microcopies while the Microbeam Listserver is dedicated to the discussion of electron microprobe techniques. Subscribing to these listservers connects you to a tremendous resource for all aspects of microscopy and microanalysis. Learn more about MSA's listserver at:

http://www.msa.microscopy.com/microscopyListserver/MLInstructions. html and MAS's listserver at:

http://www.microanalysis.org/mas/maslistserver/maslistserver.'html

WARNING: It is quite easy to get answers to questions posed on the listserver, but the answers may be to the wrong question; that is, the respondent may have misunderstood your question or symptom.

\section{Conclusion}

Many microscopists perform basic repairs and maintenance themselves. They do so either because they have little or no funding for service, or they do have a service contract but can get their scope back on-line faster themselves. Acquiring the skills necessary to handle routine maintenance and repairs is not an impossible task. It is, in fact, both challenging and rewarding. Remember, do not get in over your head. Ask for help when you need it. Proceed in a cautious, measured manner as described here and use all the resources available. There is little doubt that you can reduce your lab expenses and maintain or even improve the amount of up-time on your scope.

Bertin, E.P. 1984. Principles and Practice of X-Ray Spectrometric Analysis, 2nd Ed., Plenum Press: New York,NY

Bigelow, W.C. 1994. Vacuum Methods in Electron Microscopy, Practical Methods in Electron Microscopy vol.15, A.M. Glauert, Ed., Portland Press: Brookfield, VT. Chapman, S.K 1986. Maintaining and Monitoring the Transmission Electron Microscope, RMS Microscopy Handbook \#8, C. Hammond, Ed., Oxford University Press: New York, NY.

Goldstein, J.I., D.E. Newbury, P. Echlln, D.C. Joy, A.D. Romig, C.E. Lyman, C. Fiori, E. Lifshin. 1992. Scanninq Electron Microscopy and X-Ray Microanalysis: A Text for Biologists, Material Scientists, and Geologists, 2nd ed.. Plenum Press: New York, NY.

Williams, C.B.. D.B. Carter, 1996, Transmission Electron Microscopy: A Text for Materials Science, Plenum Press, New York, NY.

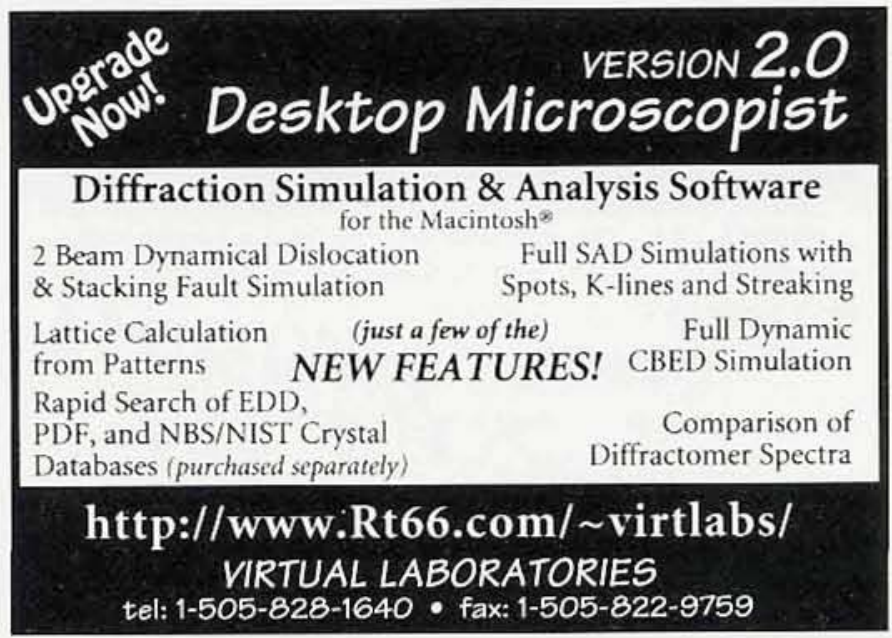

